\title{
Incidence and risk factors of neonatal infections in a rural Bangladeshi population: a community-based prospective study
}

Dipak K. Mitra', Luke C. Mullany², Meagan Harrison², Ishtiaq Mannan ${ }^{3}$, Rashed Shah ${ }^{4}$, Nazma Begum², Mamun Ibne Moin ${ }^{2}$, Shams El Arifeen ${ }^{5}$, Abdullah H. Baqui ${ }^{2^{*}}$ and For the Projahnmo Study Group in Bangladesh

\begin{abstract}
Background: Infections cause about one fifth of the estimated 2.7 million annual neonatal deaths worldwide. Population-based data on burden and risk factors of neonatal infections are lacking in developing countries, which are required for the appropriate design of effective preventive and therapeutic interventions in resource-poor settings.

Methods: We used data from a community-based cluster-randomized trial conducted to evaluate the impact of two umbilical cord cleansing regimens with chlorhexidine solution on neonatal mortality and morbidity in a rural area of Sylhet District in Bangladesh. Newborns were assessed four times in the first 9 days of life by trained community health workers (CHWs) using a WHO IMCl-like clinical algorithm. Cumulative incidence of the first episode of infections in the first 9 days of life was estimated using survival analysis technique accounting for survival bias and competing risk of death before the occurrence of infection. A multivariable generalized estimating equation log-binomial regression model was used to identify factors independently associated with infections.

Results: Between 2007 and 2009, 30,267 newborns who received at least one postnatal assessment visit by a CHW within the first 9 days of life were included in this study. Cumulative incidence of infections in the first 9 days of life was $14.5 \%$ (95\% Cl 14.1-14.9\%). Significant risk factors included previous child death in the family [RR $1.10(95 \% \mathrm{Cl} 1.02-1.19)]$; overcrowding [RR 1.14 (95\% Cl 1.04-1.25)]; home delivery [RR 1.86 (95\% Cl 1.58-2.19)]; unclean cord care [RR 1.15 (95\% Cl 1.03-1.28)]; multiple births [RR 1.34 (95\% Cl 1.15-1.56)]; low birth weight [reference: $\geq 2500 \mathrm{~g}$, RR (95\% Cl) for < 1500, 1500-1999, and 2000-2499 g were 4.69 (4.01-5.48), 2.15 (1.92-2.42), and 1.15 (1.07-1.25) respectively]; and birth asphyxia [RR 1.65 (1.51-1.81)]. Higher pregnancy order lowered the risk of infections in the study population [compared to first pregnancy, RR (95\% Cl) for second, third, and $\geq$ fourth pregnancy babies were 0.93 (0.85-1.02), 0.88 (0.79-0.97), and 0.79 (0.71-0.87), respectively].

(Continued on next page)
\end{abstract}

\footnotetext{
* Correspondence: abaqui@jhu.edu

${ }^{2}$ International Center for Maternal and Newborn Health, Department of International Health, Johns Hopkins Bloomberg School of Public Health, Johns Hopkins University, Baltimore, MD, USA

Full list of author information is available at the end of the article
} 
(Continued from previous page)

Conclusion: Neonatal infections and associated deaths can be reduced by identifying and following up highrisk mothers and newborns and promoting facility delivery and clean cord care in resource-poor countries like Bangladesh where the burden of clinically ascertained neonatal infections is high. Further research is needed to measure the burden of infections in the entire neonatal period, particularly in the second fortnight and its association with essential newborn care.

Trial registration: NCT00434408. Registered February 9, 2007.

Keywords: Neonatal infections, Risk factors, Bangladesh, Prospective study

\section{Background}

Globally, an estimated 2.7 million neonates (1-28 days) die every year, and approximately $98 \%$ of these deaths occur in developing countries $[1,2]$. Although neonatal mortality is declining, the rate of such decline has been slower than that observed for postneonatal and 1 to 4year-old child mortality [3, 4]. Thus, neonatal death is increasingly becoming more important as a proportion of under-five child deaths globally. In $2000,38 \%$ of the under-five child deaths was due to neonatal deaths, and by 2013 , this proportion became $44 \%[5,6]$. Infections including sepsis, meningitis, pneumonia, and tetanus are responsible for $22.2 \%$ of neonatal mortality globally and up to $50 \%$ of neonatal deaths in high mortality settings [7-9]. Neonatal deaths can be prevented with low-cost interventions at community and primary care facilities $[10,11]$. It has been estimated that timely identification and management of serious infections can reduce 20 to $55 \%$ of neonatal deaths with $90 \%$ service coverage, and further reduction can be achieved in conjunction with additional antenatal and intrapartum care [10, 12]. Recent evidence demonstrating the effectiveness of simpler antibiotic regimens for management of newborn infections that can be delivered at the first-level health facilities has the potential to greatly expand access to care and reduce mortality [13, 14]. Data on burden and risk factors of community-acquired neonatal infections in developing countries are scant but are critically essential for designing and implementing targeted interventions in such settings [15]. Using data from a large community-based study that evaluated the impact of chlorhexidine cleansing of the umbilical cord on neonatal mortality and morbidity, this paper provides an estimate of incidence of clinically ascertained communityacquired neonatal infections in the first 9 days of life and identifies risk factors for infections in the first 9 days of life of neonates in a rural area of Bangladesh.

\section{Methods}

\section{Study design and participants}

This study uses observational data from a cohort of newborns and their mothers that participated in a community-based trial conducted in three rural sub- districts (Beanibazar, Zakigonj, and Kanaighat) of Sylhet District in Bangladesh. Detailed design, procedure, and major findings of the trial have been described elsewhere $[16,17]$. Briefly, the study evaluated the impact of two regimens of umbilical cord cleansing (single application and 7-day application) with $4.0 \%$ chlorhexidine solution compared to dry cord care on overall neonatal mortality and incidence of cord infections (ClinicalTrials.gov identifier: NCT0043448). An estimated 546,000 population in 22 unions (the smallest administrative unit with $\sim 25,000$ populations with a first-level health facility) participated in the study. The area was divided into 133 clusters, each served by a female community health worker (CHW) and 4-5 village health workers (VHWs), who implemented the interventions and collected data.

\section{Study procedures}

CHWs enumerated all households at the beginning of the study and made a list of married women of reproductive age (MWRA) including their pregnancy status in the study area. They continued two monthly home visits to update the list of MWRAs and to identify new pregnant women. All women identified as pregnant during the study period were invited to participate in the study. Those agreeing to participate provided data on age, parity, date of last menstrual period, occupation, literacy, complete birth history, and socio-economic information of the household.

CHWs delivered a package of maternal and neonatal health interventions to all enrolled women during the two antenatal home visits made at 12-16 weeks and at 32-34 weeks of pregnancy. The intervention package included a supply of iron and folic acid, a clean birthing kit, messages on birth and newborn care preparedness (BNCP), and advice on essential newborn care (clean cord care, breastfeeding, and thermal care), and postnatal danger signs [11, 17]. CHWs made six postnatal home visits scheduled on days $1,3,6,9,15$, and 28-35 to deliver interventions and collect data. Physical assessment for signs of clinical infections was performed in the first four visits. All live births in the study areas that received at least one postnatal assessment visit by $\mathrm{CHW}$ in the first 9 days of life were included in this study. 


\section{Training and quality assurance}

All CHWs received in-house and competence-based training for 6 weeks under the direct supervision of trained physicians. The training sessions used a standard curriculum including skills development for behavior change communication, delivery of BNCP and essential newborn care, clinical assessment of neonates, and identification and management of sick newborns using the clinical algorithm. After the training, all CHWs were standardized for clinical assessment in Sylhet MAG Osmani Medical College Hospital, a tertiary care teaching hospital serving the study population. Field data quality was ensured through direct supervision by field supervisors. Periodic supervisory visits and standardization exercise sessions were organized to ensure data quality. Data forms were edited by supervisory staff for completeness, accuracy, and consistency. Data entry system was designed with built-in range and consistency checks. All identified incomplete or inconsistent data were verified in the field by senior project staff.

\section{Follow-up visits and data collection Exposure variables}

CHWs collected information on exposure variables during antenatal visits and the first postnatal visit using a set of questionnaires and assessment tools. Information on socio-demographic and economic variables (age at enrollment, educational status of women and their husbands, basic housing structure, sanitation and source of drinking water, household assets, religion, household size) and previous obstetric history were collected at enrollment. Data on antenatal care, consumption of iron tablets, TT immunization, and antenatal complications (history of fever, severe abdominal pain, swelling of hand, leg or face, vaginal bleeding, convulsion, severe headache, blurring of vision) were collected from all women during antenatal visits and the first postnatal visit. Information on delivery characteristics (date and time of birth, birth attendants, place of birth, prolonged labor, prolonged rupture of membrane, retained placenta, cord care), newborn characteristics (sex, birth weight, gestational age at delivery, conditions of the baby at birth), and essential newborn care (clean cord care, breastfeeding, thermal care) were collected on the first postnatal visit.

\section{Outcome variable}

The primary outcome of the study was neonatal infection during the first 9 days of life as clinically ascertained by the CHWs. During the postnatal visits scheduled on days $1,3,6$, and 9, CHWs assessed all babies who were alive on the day of the visits and recorded signs of infections and other illnesses. While most visits happened as scheduled on days 1, 3, 6, and 9, in some cases, the visits were made in the intervals, so during the analysis stage, the actual age of newborns was calculated at the time of each visit for consistency. Assessment visits beyond day 9 are excluded from this analysis. Clinical infections were defined as the presence of any of the seven signs (panel 1) on the day of assessment; these signs included the seven signs of the WHO recommended Integrated Management of Childhood Illness (IMCI) algorithm [18].

Panel 1: Clinical signs used for CHW's assessment in the study

- History of or observed convulsion

- Feeding difficulty confirmed by observation

- Respiratory rate 60 per minute or more

- Severe chest indrawing

- Temperature $\geq 37.5{ }^{\circ} \mathrm{C}$

- Temperature $\leq 35.5{ }^{\circ} \mathrm{C}$

- Does not move without stimulation

\section{Statistical analyses}

We estimated the cumulative incidence of neonatal infections in the first 9 days of life and 95\% confidence interval (CI) using a survival analysis technique. To minimize survival bias, we allowed late entry that babies entered the analysis at the age of first visit by $\mathrm{CHWs}$ and contributed person time until the occurrence of the first episode of infection, death, lost to follow-up, or reaching age day 9. Death before the occurrence of infection was considered a competing risk and was adjusted in the estimation procedure, as a conventional Kaplan-Meier estimator is likely to overestimate cumulative incidence in the presence of a competing risk such as death [19]. We used Stata command "stcompet" written by Enzo Coviello for this purpose [20].

Risk factor analysis was done using a log-binomial regression with a log link function and binomial family. A generalized estimating equation (GEE) approach with exchangeable correlation structure was used to adjust for the clustered nature of the data $[21,22]$. The $\mathrm{CHW}$ working area was considered as the cluster in our analysis due to variation in case detection proportion by CHWs. In case of convergence failure with log-binomial model, a Poisson regression with a robust standard error was used [23]. Missing data of covariates were imputed using the "hotdeck" method by cluster [24].

The exposure variables were grouped into (1) sociodemographic and household factors (maternal age, birth order, parental educational status, household crowding, previous history of child deaths, household economic status), (2) maternal factors (obstetric history, antenatal care, delivery characteristics), and (3) newborn factors (sex, gestational age, birth weight, condition of the baby at birth, essential newborn care). For measuring socio- 
economic status, a categorical wealth index variable was created using information on ownership of durable household assets, source of drinking water, type of latrine, and characteristics of dwelling house using principal component analysis [25]. In our final model, variables related to the initiation of breastfeeding, oil massage, and delaying bathing the baby were excluded as early morbidities are likely to negatively influence these newborn care practices [26]. Data analyses were done in Stata (version 12) statistical software [27].

\section{Results}

Between June 2007 and September 2009, 35,908 live births were recorded in the study population. CHWs made at least one postnatal home visit in 33,138 babies (92.3\%), and of these, 2871 (8.66\%) were excluded; 495 (17.2\%) due to death before CHW's visit; 581 (20.2\%) due to missing assessment data; and 1795 (62.5\%) due to first postnatal visit after day 9. Overall, 3592 babies developed first episode neonatal infections during the follow-up period (Fig. 1).
Cumulative incidence of neonatal infections (Fig. 2) in the first 9 days of life was $14.5 \%$ (95\% CI $14.1-$ $14.9 \%)$, and in the first week of life, it was $13.4 \%$ (95\% CI $12.9-13.8 \%$ ).

Table 1 summarizes socio-demographic and household factors and their crude association with neonatal infections. Neonates in the lower four household wealth quintiles had increased risk of infections compared to those in the highest wealth quintile. Higher education levels of mothers ( $\geq$ primary) significantly decreased the risk of infection in newborns, but father's education level did not have any significant association. Babies born in families with $\leq 0.5$ bedrooms per person (a proxy of crowding) had a significantly higher risk of infection compared to babies in families with $>0.5$ bedrooms per person [RR 1.15 (95\% CI 1.06-1.25)].

Table 2 shows maternal factors and their association with neonatal infections. Compared to babies born in first pregnancies, third and higher pregnancy order babies had a significantly lower risk of infection. Maternal iron intake for $\geq 60$ days during pregnancy was associated with lower risk of neonatal infections (RR 0.91;

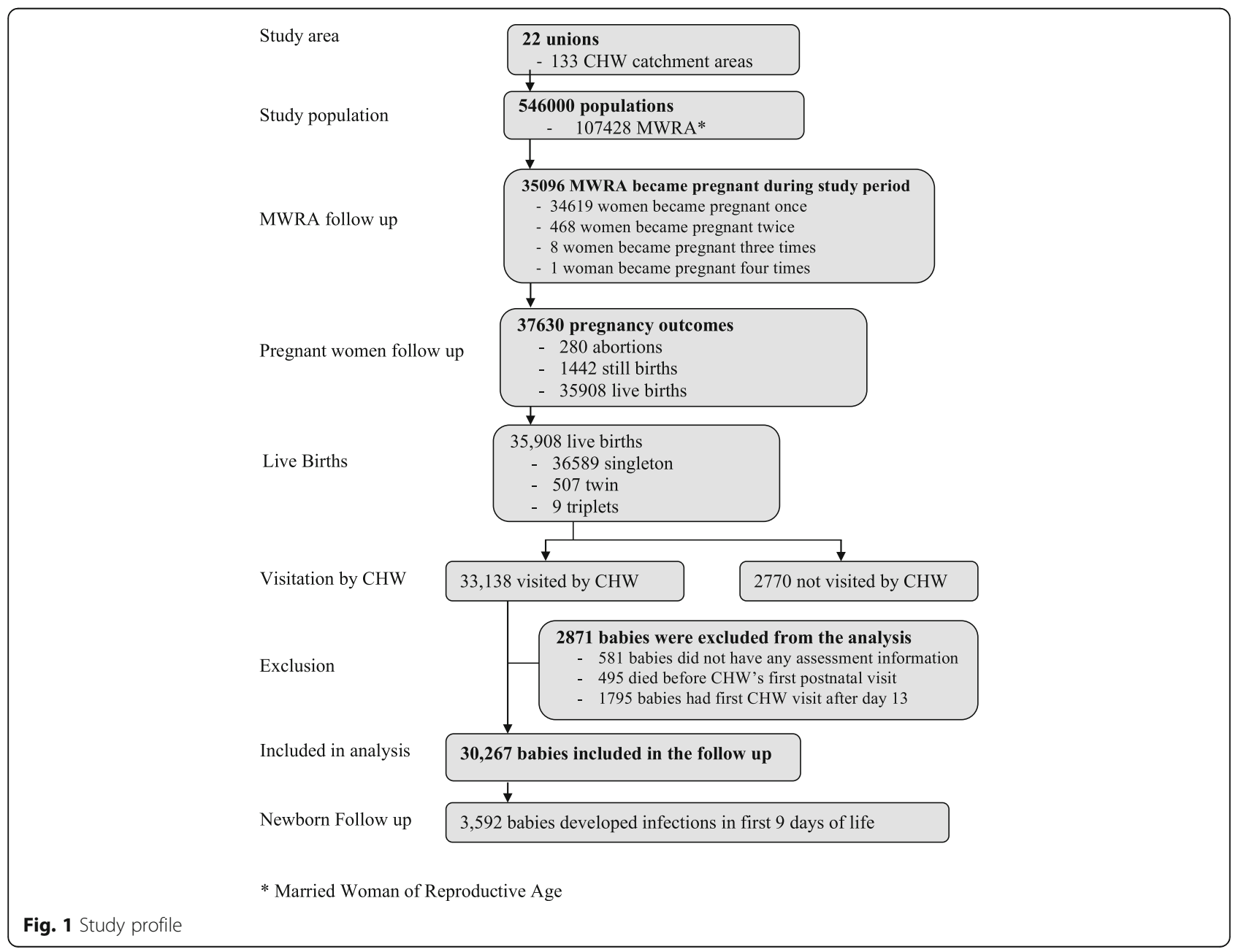




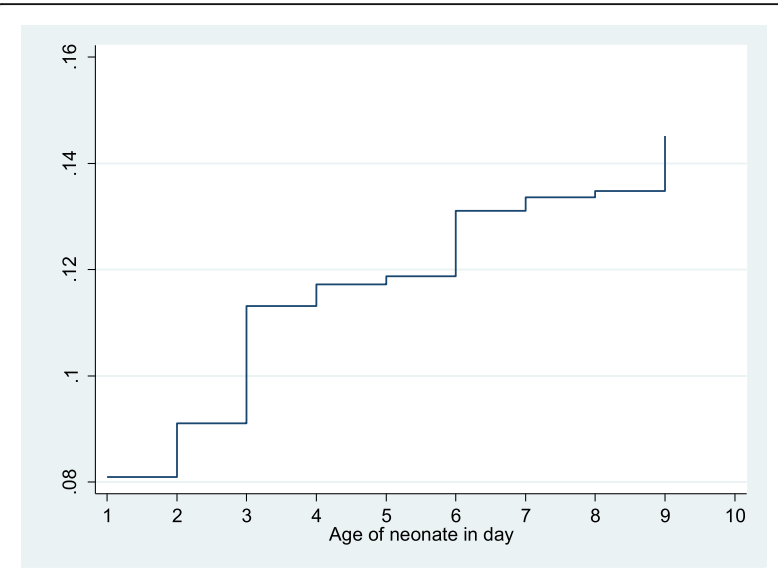

Fig. 2 Cumulative incidence of neonatal infections in the first 9 days adjusted for competing risk of deaths
95\% CI 0.85-0.97) compared to iron intake for $<60$ days during pregnancy. Delivery by a skilled attendant significantly lowered the risk of neonatal infections compared to deliveries by unskilled attendants (RR 0.80; 95\% CI 0.72-0.90). Home-delivered babies had a higher risk of infection compared to facility-born babies [RR 1.60 $(1.37-1.85)]$. Those who reported that the birth attendants washed their hands before delivery had a lower risk of infection. Babies whose mothers had retained placenta experienced a significantly higher risk of infection (RR 1.50; 95\% CI 1.28-1.75).

Table 3 shows newborn factors and their association with neonatal infections. Multiple birth outcome babies had a significantly increased risk of infection [RR 2.47 (95\% CI 2.18-2.80)] compared to singleton babies. Lower birth weights significantly increased the risk of infections. Compared to $\geq 2500 \mathrm{~g}$ babies, RRs (95\% CI) were 6.50 (5.74-7.47), 2.55 (2.29-2.83), and 1.20 (1.121.29) for < 1500, 1500-1999, and 2000-2499 g babies,

Table 1 Association of socio-demographic and household factors with neonatal infections

\begin{tabular}{|c|c|c|c|c|c|}
\hline \multirow[t]{2}{*}{ Characteristics } & \multicolumn{5}{|c|}{ Neonatal infections in first 2 weeks $(n=30,267)$} \\
\hline & Number & Infections & Percent & $\mathrm{RR}$ & $95 \% \mathrm{Cl}$ \\
\hline \multicolumn{6}{|l|}{ Household wealth quintile } \\
\hline Lowest quintile (poorest) & 6089 & 755 & 12.4 & 1.16 & $1.04-1.29$ \\
\hline Second lowest quintile & 6020 & 749 & 12.4 & 1.16 & $1.05-1.29$ \\
\hline Middle quintile & 6052 & 731 & 12.1 & 1.12 & $1.02-1.24$ \\
\hline Second highest quintile & 6053 & 744 & 12.3 & 1.14 & $1.03-1.26$ \\
\hline Highest quintile (richest) & 6053 & 613 & 10.1 & 1.00 & \\
\hline \multicolumn{6}{|l|}{ Religion } \\
\hline Islam & 28,934 & 3445 & 11.9 & 1.00 & \\
\hline Others & 1333 & 147 & 1105 & 0.98 & $0.84-1.15$ \\
\hline \multicolumn{6}{|l|}{ Mother's age } \\
\hline$<25$ years & 9994 & 1291 & 12.9 & 1.00 & \\
\hline $25-29$ years & 10,220 & 1098 & 10.71 .0 & 0.85 & $0.79-0.92$ \\
\hline 30-34 years & 6180 & 746 & 12.1 & 0.97 & $0.90-1.06$ \\
\hline 35 years and above & 3873 & 457 & 11.8 & 0.96 & $0.87-1.06$ \\
\hline \multicolumn{6}{|l|}{ Mother's education } \\
\hline Below primary level & 15,266 & 1911 & 12.5 & 1.00 & \\
\hline Primary and above & 15,001 & 1681 & 11.2 & 0.93 & $0.87-0.99$ \\
\hline \multicolumn{6}{|l|}{ Father's education } \\
\hline Below primary level & 17,607 & 2147 & 12.2 & 1.00 & \\
\hline Primary and above & 12,660 & 1445 & 11.4 & 0.98 & $0.92-1.04$ \\
\hline \multicolumn{6}{|l|}{ History of child death } \\
\hline Yes & 7499 & 938 & 12.5 & 1.07 & $0.99-1.15$ \\
\hline No & 22,768 & 2654 & 1179 & 1.00 & \\
\hline \multicolumn{6}{|l|}{ Sleeping room per person } \\
\hline 0.5 or less & 24,854 & 3014 & 12.1 & 1.15 & $1.06-1.25$ \\
\hline Higher than 0.5 & 5413 & 578 & 10.7 & 1.00 & \\
\hline
\end{tabular}


Table 2 Association of pregnancy and delivery characteristics with neonatal infections

\begin{tabular}{|c|c|c|c|c|c|}
\hline \multirow[t]{2}{*}{ Characteristics } & \multicolumn{5}{|c|}{ Neonatal infections in first 2 weeks $(n=30,267)$} \\
\hline & Number & Infections & Percent & Risk ratio & $95 \% \mathrm{Cl}$ \\
\hline \multicolumn{6}{|l|}{ Pregnancy order } \\
\hline First & 5523 & 729 & 13.2 & 1.00 & \\
\hline Second & 5831 & 705 & 12.1 & 0.91 & $0.83-1.00$ \\
\hline Third & 5187 & 592 & 11.4 & 0.85 & $0.77-0.94$ \\
\hline Fourth or higher & 13,726 & 1566 & 11.4 & 0.85 & $0.79-0.92$ \\
\hline \multicolumn{6}{|c|}{ Iron consumption during pregnancy } \\
\hline Less than 60 days & 12,349 & 1597 & 12.9 & 1.00 & \\
\hline 60 days or more & 17,918 & 1995 & 11.1 & 0.91 & $0.85-0.97$ \\
\hline
\end{tabular}

ANC from qualified provider

$\begin{array}{llllll}\text { Yes } & 16,056 & 1867 & 11.6 & 1.07 & 0.99-1.14 \\ \text { No } & 14,211 & 1725 & 12.1 & 1.00 & \end{array}$

Antenatal complications

$\begin{array}{lllll}\text { Yes } & 6161 & 793 & 12.9 & 1.07 \\ \text { No } & 24,106 & 2799 & 11.6 & 1.00\end{array}$

Birth attendant*

$\begin{array}{lllll}\text { Skilled } & 3118 & 269 & 8.63 & 0.80 \\ \text { Unskilled } & 27,149 & 3323 & 12.2 & 1.00 \\ \begin{array}{llll}\text { Place of delivery } \\ \text { Home }\end{array} & & & & \\ \text { Facility } & 27,882 & 3430 & 12.3 & 1.60 \\ & 2385 & 162 & 6.8 & 1.00\end{array}$

Washed hands before delivery

$\begin{array}{lllll}\text { Yes } & 29,138 & 3415 & 11.7 & 0.83 \\ \text { No } & 1129 & 177 & 15.7 & 1.00\end{array}$

Prolonged labor

$\begin{array}{lllll}\text { Yes } & 2708 & 328 & 11.8 & 1.08 \\ \text { No } & 27,559 & 3264 & 12.1 & 1.00\end{array}$

Prolonged rupture of membrane

\begin{tabular}{llllll} 
Yes & 2082 & 276 & 13.3 & 1.08 & $0.96-1.21$ \\
No & 28,185 & 3316 & 11.8 & 1.00 & \\
Retained placenta & & & & & \\
Yes & 753 & 150 & 19.9 & 1.50 & $1.28-1.75$ \\
No & 29,514 & 3442 & 11.7 & 1.00 & \\
\hline
\end{tabular}

*Health care providers including physicians, nurses, and paramedics and midwives who have midwifery training for at least 6 months are considered as skilled birth attendants

respectively. Asphyxiated babies had 1.87 (95\% CI 1.732.03) times higher risk of infections than babies with no signs of asphyxia at birth.

Table 4 shows the results from a multivariable GEE log-binomial model. Model 1 is the full model with all covariates, and model 2 is the final model excluding variables based on collinearity and reverse causality. Higher pregnancy order significantly decreased the risk of infections. Compared to the first pregnancy babies,
Table 3 Association of newborn characteristics with neonatal infections

\begin{tabular}{|c|c|c|c|c|c|}
\hline \multirow[t]{2}{*}{ Characteristics } & \multicolumn{5}{|c|}{ Neonatal infections in first 2 weeks $(n=30,267)$} \\
\hline & Number & Infections & Percent & RR & $95 \% \mathrm{Cl}$ \\
\hline \multicolumn{6}{|l|}{ Single/multiple birth } \\
\hline Singleton & 29,558 & 3386 & 11.5 & 1.00 & \\
\hline Multiple birth & 709 & 206 & 29.1 & 2.47 & $2.18-2.80$ \\
\hline \multicolumn{6}{|l|}{ Gestational age at birth } \\
\hline$<35$ weeks & 2693 & 442 & 16.4 & 1.44 & $1.31-1.58$ \\
\hline 35-36 weeks & 3546 & 415 & 11.7 & 1.04 & $0.95-1.15$ \\
\hline 37 weeks or more & 24,028 & 2735 & 11.4 & 1.00 & \\
\hline \multicolumn{6}{|l|}{ Sex of the baby } \\
\hline Male & 15,646 & 1880 & 12.0 & 1.00 & \\
\hline Female & 14,621 & 1712 & 11.7 & 0.97 & $0.92-1.03$ \\
\hline \multicolumn{6}{|l|}{ Birth weight } \\
\hline$<1500 \mathrm{~g}$ & 210 & 142 & 67.6 & 6.50 & $5.74-7.37$ \\
\hline $1500-1999 \mathrm{~g}$ & 1369 & 357 & 26.1 & 2.55 & $2.29-2.83$ \\
\hline $2000-2499 \mathrm{~g}$ & 8386 & 1040 & 12.4 & 1.20 & $1.12-1.29$ \\
\hline $2500 \mathrm{~g}$ or higher & 20,302 & 2053 & 10.1 & 1.00 & \\
\hline \multicolumn{6}{|l|}{ Birth asphyxia } \\
\hline Yes & 3427 & 709 & 20.7 & 1.87 & $1.73-2.03$ \\
\hline No & 26,840 & 2883 & 10.7 & 1.00 & \\
\hline \multicolumn{6}{|c|}{ Sterile cord cutting and tying } \\
\hline Yes & 26,291 & 3122 & 11.9 & 1.08 & $0.98-1.18$ \\
\hline & & & & & \\
\hline
\end{tabular}

Non-study substances on cord

$\begin{array}{llllll}\text { Yes } & 1779 & 236 & 13.3 & 1.05 & 0.92-1.20 \\ \text { No } & 28,488 & 3356 & 11.8 & 1.00 & \\ \text { Dried within 30 min } & & & & & \\ \text { Yes } & 25,719 & 2893 & 11.3 & 1.00 & \\ \text { No } & 4548 & 699 & 15.4 & 1.18 & 1.08-1.28\end{array}$

Wrapped within $30 \mathrm{~min}$

$\begin{array}{llllll}\text { Yes } & 25,321 & 2828 & 11.2 & 1.00 & \\ \text { No } & 4946 & 764 & 15.5 & 1.20 & 1.10-1.31\end{array}$

Breastfed within $1 \mathrm{~h}$

$\begin{array}{llllll}\text { Yes } & 18,329 & 2093 & 11.4 & 1.00 & \\ \text { No } & 11,938 & 1499 & 12.6 & 1.05 & 0.98-1.13\end{array}$

Oil massaged within $1 \mathrm{~h}$

\begin{tabular}{lccccc} 
Yes & 3292 & 437 & 13.3 & 1.11 & $1.00-1.23$ \\
No & 26,975 & 3155 & 11.7 & 1.00 & \\
Delayed bath for 1 day & & & & \\
Yes & 26,519 & 3084 & 11.6 & 1.10 & $0.99-1.21$ \\
No & 3748 & 508 & 13.6 & 1.00 & \\
\hline
\end{tabular}

RR (95\% CI) of the second, third, and $\geq$ fourth pregnancy babies were 0.93 (0.85-1.02), 0.88 (0.79-0.97), and $0.79(0.71-0.87)$, respectively. Babies born in 
Table 4 Risk factors of neonatal infections from multivariable GEE log-binomial regression

\begin{tabular}{|c|c|c|c|c|}
\hline \multirow[t]{2}{*}{ Risk factors } & \multicolumn{2}{|c|}{ Model 1 (full) } & \multicolumn{2}{|c|}{ Model 2 (final) } \\
\hline & Risk ratio & $95 \% \mathrm{Cl}$ & Risk ratio & $95 \% \mathrm{Cl}$ \\
\hline \multicolumn{5}{|l|}{ Household wealth quintile (ref: highest quintile) } \\
\hline Lowest quintile (poorest) & 1.05 & $0.95-1.17$ & 1.04 & $0.94-1.16$ \\
\hline Second lowest quintile & 1.06 & $0.96-1.18$ & 1.06 & $0.96-1.17$ \\
\hline Middle quintile & 1.03 & $0.93-1.14$ & 1.02 & $0.93-1.14$ \\
\hline Second highest quintile & 1.08 & $0.98-1.19$ & 1.07 & $0.97-1.19$ \\
\hline Non-Muslims (ref: Muslim) & 0.96 & $0.84-1.10$ & 0.96 & $0.84-1.10$ \\
\hline \multicolumn{5}{|l|}{ Mother's age (ref: $<25$ years) } \\
\hline $25-29$ years & 0.94 & $0.87-1.02$ & 0.94 & $0.87-1.03$ \\
\hline 30-34 years & 1.10 & $1.00-1.21$ & 1.10 & $1.00-1.21$ \\
\hline 35 years and above & 1.08 & $0.96-1.22$ & 1.09 & $0.96-1.23$ \\
\hline Mothers primary or above (ref: below primary) & 0.94 & $0.87-1.02$ & 0.94 & $0.87-1.02$ \\
\hline Father's primary and above (ref: below primary) & 1.08 & $1.00-1.16$ & 1.08 & $1.00-1.16$ \\
\hline \multicolumn{5}{|l|}{ Pregnancy order (ref: first pregnancies) } \\
\hline Second & 0.93 & $0.85-1.02$ & 0.93 & $0.85-1.02$ \\
\hline Third & 0.88 & $0.79-0.97$ & 0.88 & $0.79-0.97$ \\
\hline Fourth or higher & 0.79 & $0.71-0.87$ & 0.79 & $0.71-0.87$ \\
\hline History of child death (ref: no history of death) & 1.10 & $1.02-1.19$ & 1.10 & $1.02-1.19$ \\
\hline$\leq 0.5$ room per person in the house (ref: $>0.5$ ) & 1.14 & $1.04-1.26$ & 1.14 & $1.04-1.25$ \\
\hline Antenatal iron consumption for $\geq 60$ days (ref: $<60$ days) & 0.96 & $0.89-1.03$ & 0.96 & $0.89-1.03$ \\
\hline ANC from qualified provider (ref: no) & 1.11 & $1.03-1.19$ & 1.11 & $1.03-1.19$ \\
\hline Antenatal complications (ref: no complications) & 1.01 & $0.92-1.10$ & 1.01 & $0.92-1.10$ \\
\hline Home delivery (ref: facility delivery) & 2.13 & $1.73-2.62$ & 1.86 & $1.58-2.19$ \\
\hline Skilled birth attendant (ref: unskilled attendant) & 1.19 & $1.01-1.40$ & & \\
\hline Washed hands before delivery (ref: no) & 0.92 & $0.77-1.09$ & & \\
\hline Prolonged labor (ref: no) & 1.04 & $0.93-1.16$ & 1.04 & $0.94-1.16$ \\
\hline Prolonged rupture of membrane (ref: no) & 1.02 & $0.91-1.14$ & 1.02 & $0.92-1.14$ \\
\hline Retained placenta (ref: no) & 1.15 & $0.98-1.35$ & 1.14 & $0.96-1.34$ \\
\hline Non-study substances on cord (ref: no) & 0.96 & $0.85-1.09$ & 0.96 & $0.85-1.09$ \\
\hline Non-sterile cord cutting and tying (ref: sterile) & 1.13 & $1.02-1.25$ & 1.15 & $1.03-1.28$ \\
\hline Multiple birth (ref: singleton birth) & 1.33 & $1.15-1.55$ & 1.34 & $1.15-1.56$ \\
\hline Female baby (ref: male baby) & 0.96 & $0.90-1.02$ & 0.96 & $0.89-1.02$ \\
\hline \multicolumn{5}{|l|}{ Gestational age at birth (ref: $\geq 37$ weeks) } \\
\hline$<35$ weeks & 1.09 & $0.99-1.19$ & 1.08 & $0.99-1.19$ \\
\hline 35-36 weeks & 0.97 & $0.87-1.07$ & 0.96 & $087-1.07$ \\
\hline \multicolumn{5}{|l|}{ Birth weight (ref: $\geq 2500 \mathrm{~g}$ ) } \\
\hline$<1500 \mathrm{~g}$ & 4.70 & $4.01-5.51$ & 4.69 & $4.01-5.48$ \\
\hline $1500-1999 \mathrm{~g}$ & 2.15 & $1.92-2.41$ & 2.15 & $1.92-2.42$ \\
\hline $2000-2499 \mathrm{~g}$ & 1.16 & $1.07-1.25$ & 1.15 & $1.07-1.25$ \\
\hline Birth asphyxia (ref: no birth asphyxia) & 1.66 & $1.51-1.82$ & 1.65 & $1.51-1.81$ \\
\hline Dried baby after 30 min (ref: < $30 \mathrm{~min}$ ) & 0.93 & $0.66-1.30$ & 0.94 & $0.73-1.20$ \\
\hline Wrapped after 30 min (ref: < 30 min) & 1.20 & $0.96-1.51$ & 1.19 & $0.95-1.49$ \\
\hline Breastfed after 1 h (ref: within 1 h) & 0.96 & $0.84-1.09$ & & \\
\hline Oil massaged within $1 \mathrm{~h}$ (ref: no massage within 1 h) & 1.03 & $0.91-1.16$ & & \\
\hline Bathed baby within 1 day (ref: delayed bath for 1 day) & 1.01 & $0.78-1.32$ & & \\
\hline
\end{tabular}


families with a previous history of child deaths were more likely to develop infections [RR 1.10 (95\% CI 1.021.19)]. Neonates born in crowded families $(\leq 0.5$ bedrooms per person) had increased risk of acquiring infections [RR 1.14 (95\% CI 1.04-1.25)]. Receipt of antenatal care from qualified providers during pregnancy increased the risk of infections in the neonates [RR 1.11 (95\% CI 1.03-1.19)]. Home-born babies had a significantly higher risk of infections compared to facility-born babies [RR 1.86 (95\% CI 1.58-2.19)]. Non-sterile cutting and tying of the umbilical cord significantly increased the risk of neonatal infections in the study population [RR 1.15 (95\% CI 1.03-1.28)]. Multiple birth babies had a significantly higher risk of infections [RR 1.34 (95\% CI: 1.15-1.56)] compared to singleton babies. Lower birth weight significantly increased the risk of infections. Compared to $\geq 2500 \mathrm{~g}$ babies, RR (95\% CI) for < $1500 \mathrm{~g}$ babies was 4.69 (4.01-5.48), 2.15 (1.92-2.42) for 1500$1999 \mathrm{~g}$ babies, and 1.15 (1.07-1.25) for 2000-2499 g babies. Babies born with signs of birth asphyxia also had a higher risk of infections [RR 1.65 (95\% CI 1.51-1.81)].

\section{Discussions}

We report high cumulative incidence (14.5\%) of infections as ascertained by CHWs in four scheduled postnatal visits in the first 9 days of life in our study population. We also demonstrate that multiple socio-demographic, household, maternal, and newborn characteristics are significantly associated with neonatal infections. These data come from a well-defined large $(n=30,267)$ population-based birth cohort in a rural area of Bangladesh. Comparison between estimates of clinical neonatal infections estimated in different studies is challenging due to the use of variable clinical algorithms, duration of follow-up, and frequency of assessment. Our estimate is higher than the previous estimates from the same setting. Baqui et al. (2009) reported 5.6\% incidence of very severe disease and $11.2 \%$ possible very severe disease in the first week of life from this study area [28]. Although the estimates appear similar, the duration of follow-up, frequency of assessment, and clinical algorithms are different. Estimates from India, Nepal, and Pakistan used a similar clinical algorithm but used variable follow-up duration and assessment schedule ranges from 5.0 to $11.0 \%$ [29].

Our data shows that higher birth order decreased the risk of neonatal infections, which is consistent with the findings from other studies. One study from Sweden reported an odds ratio of 0.56 (95\% CI $0.45-0.70)$ for multiparity compared to primiparity [30]. Another study in Nepal found babies born to primipara mothers had a higher risk of infection (OR 1.58) compared to babies of multipara mothers [31]. These findings are likely to occur due to the improved newborn care practices by experienced mothers, particularly early initiation of breastfeeding [32].
Previous death of a child in the family is an established risk factor for child death [33]. However, reports on its association with immediate contributors of neonatal deaths are mixed. One study in Nepal did not find any association between previous child deaths and asphyxiarelated neonatal death [34]; however, other studies showed its association with preterm birth or small for gestational age $[35,36]$. With this study, now we show that previous child death is associated with early neonatal infections. Density of people in the household has also been shown to increase the risk of child mortality in different settings $[37,38]$. Our data show that $<1$ room per two persons significantly increased the risk of neonatal infections. Increased density of people in the household represents overcrowding, which contributes to the transmission of infections through respiratory droplets [39, 40]. We found an increased risk of infections in babies born to mothers who received at least one antenatal care (ANC) visit from a qualified provider compared to babies whose mothers did not receive any ANC visits from qualified providers. This finding contradicts the generally held belief that ANC reduces the risk of neonatal infections and mortality [41]. This could have resulted from misclassification between routine ANC and care seeking for antenatal complications, as both data are collected as maternal reports. Homedelivered newborns were at greater risk of developing infections compared to facility-born babies in our study population, which is consistent with the findings from other studies [42, 43]. Although home-born babies received their first assessment visits by $\mathrm{CHWs}$ much earlier than the hospital-born babies (median age at first visit in home-delivered babies $15 \mathrm{~h}$ compared to $78 \mathrm{~h}$ in facility-born babies), the association remained significant even after adjusting for age at first visit. Prolonged duration of labor and prolonged rupture of membrane (PROM) were not associated with neonatal infections, although others have found that these conditions are associated with newborn infection [44, 45]. Failure to cut and tie the umbilical cord aseptically increased the risk of infections significantly. This supports that the clean cord practice can prevent neonatal infections and deaths in settings where most births occur at home [46]. In this study, babies born in multiple births were at higher risk of infections compared to singleton babies, which is consistent with the reports in previous studies [47]. We did not find any elevated risk associated with male sex as reported in earlier studies [31, 48]. Gestational age at birth was not associated with neonatal infections in the adjusted model, but birth weight was highly associated, although both preterm and low birth weight are established risk factors for neonatal infections [49]. Birth asphyxia is significantly associated with infections, as was also reported in the previous studies $[49,50]$. 
This study has several strengths. This is a large population-based study in a developing country setting with routine pregnancy and birth surveillance in place. The study enrolled a large number of newborns allowing adequate sample size for estimating the incidence of neonatal infections with high precision. The study also provides adequate samples for testing hypotheses for smaller associations with high power. All risk factors were measured before the occurrence of outcomes that allowed eliminating certain biases that are common in cross-sectional studies. We adjusted for survival bias allowing late entry at the age of health workers' first assessment and competing risk of deaths for estimating cumulative incidence function of infections.

The study also had several limitations. The algorithm used for the diagnosis of neonatal infections may have high sensitivity and low specificity, and the clinical algorithm used to ascertain newborn infections overlaps with prematurity, LBW, and birth asphyxia [51]. Laboratory diagnosis of infection was not performed in this study. Although the presence of interventions may have influenced the incidence of infections, the analysis of risk factors was adjusted for intervention effects. This study captured infections in the first 2 weeks of life; thus, the findings do not represent infections in the entire neonatal period. However, this is the most vulnerable period accounting for almost $90 \%$ of neonatal deaths in developing countries [52]. The infants who died before the CHW's first assessment were excluded from this study, resulting in left truncation and residual survival bias.

Several areas for future research are highlighted with the findings of this study. Similar studies should be conducted to capture the entire neonatal period to generate further population-based data on burden and risk factors of neonatal infections in low- and middle-income countries. The effect of essential neonatal care on late-onset infections also needs to be examined. Another area of future interest is the incidence of recurrent infections in the neonatal period and within early infancy period (i.e., the first 2 months of life).

\section{Conclusions}

In conclusion, the high burden of neonatal infections remains a major challenge to reducing neonatal deaths in Bangladesh. Several socio-economic, household, maternal, and newborn factors were shown to increase the risk of neonatal infection. About half of the cases developed signs very early on the day of birth. Two thirds of home births in Bangladesh with almost negligible outreach worker visitation coverage [53] remain as a huge challenge in terms of identification of the danger signs, early on. Thus maternal and child health programs in low- and middle-income countries should design strategies to promote preventive measures, identify and manage newborns with clinical infections at the community and first level facility, and promote facility delivery in the long run. The Ministry of Health and Family Welfare (MOH\&FW) in Bangladesh is about to launch its 4th Health, Nutrition and Population (HNP) Sector program, with a strong National Newborn Health Program (NNHP) inbuilt in it [54]. In the context of wider geographic disparity in newborn mortality in the country [53], Bangladesh needs differential program design. Keeping in alignment with recommendations from the Bangladesh Every Newborn Action Plan (BENAP) [55], the NNHP puts a strong emphasis on a comprehensive social and behavioral change communication strategy focused towards changing community norms and behavior relevant to newborn care. To be optimally effective, both the differential approach and a customized approach for SBCC strategy should draw on the risk factors identified in this study.

\section{Abbreviations}

BNCP: Birth and newborn care preparedness; CHW: Community health worker; Cl: Confidence interval; GEE: Generalized estimating equation; IMCI: Integrated Management of Childhood IIIness; LBW: Low birth weight; MWRA: Married woman of reproductive age; OR: Odds ratio; RR: Risk ratio; WHO: World Health Organization

\section{Acknowledgements}

The study was conducted by the Projahnmo study group in Bangladesh. Projhanmo is a partnership of the International Centre for Diarrheal Disease Research, Bangladesh; the Bangladesh government's Ministry of Health and Family Welfare; Shimantik (a Bangladeshi non-governmental organization); Save the Children-US; Dhaka Shishu Hospital; and the Johns Hopkins Bloomberg School of Public Health, USA. We especially thank the members of the Projahnmo study team and colleagues at the Bangladesh Ministry of Health and Family Welfare at the sub-district, district, and central levels for their valuable help and advice. We thank the many individuals in Sylhet District who gave their time generously as well as the Projahnmo field and data management staff who worked tirelessly on this study. Finally, we thank the Sylhet communities who hosted this study and especially the study participants for their participation in this study.

\section{Funding}

Funding for the parent chlorhexidine trial was provided by the United States Agency for International Development, Office of Health, Infectious Diseases, and Nutrition; Global Health Bureau and the Dhaka Mission through the Global Research Activity Cooperative Agreement (GHS-A-00-03-00019-00); and the Saving Newborn Lives initiative of Save the Children Federation-USA through a grant from the Bill and Melinda Gates Foundation. Dipak K. Mitra was supported through Fogarty Training Grant (Grant \# D43TW7587) during the period of the data analyses and manuscript writing.

The funders of the study had no role in the study design, data collection, data analysis, data interpretation, or writing of the report.

\section{Availability of data and materials}

Data and all the materials will be available from the corresponding author upon request.

\section{Authors' contributions}

DKM and AHB primarily conceptualized the design and analysis of this study. $A H B$ and LCM were primarily responsible for the design and protocol development of the parent study (chlorhexidine trial). AHB was the principal investigator of the parent study, and SEA, LCM, IM, and RS were Coinvestigators of the parent study. DKM conducted the data analyses, drafted the manuscript, and incorporated the inputs from co-authors. NB, MIM, and $\mathrm{MH}$ assisted in the data management and analyses. All authors reviewed the draft manuscript and provided inputs in finalizing the manuscript. AHB 
provided critical inputs in the data analyses and manuscript drafts and approved the final version. All authors read and approved the final manuscript.

\section{Ethics approval and consent to participate}

The study protocol was approved by the Institutional Review Board of the Johns Hopkins Bloomberg School of Public Health and the Ethical Review Committee of the International Centre for Diarrheal Disease Research, Bangladesh (icddr,b). Oral consent was obtained from each respondent prior to the data collection. Privacy and confidentiality were maintained throughout the study.

\section{Consent for publication}

Not applicable

\section{Competing interests}

The authors declare that they have no competing interests.

\section{Publisher's Note}

Springer Nature remains neutral with regard to jurisdictional claims in published maps and institutional affiliations.

\section{Author details}

'School of Public Health, Independent University, Bangladesh (IUB), Dhaka, Bangladesh. ${ }^{2}$ International Center for Maternal and Newborn Health, Department of International Health, Johns Hopkins Bloomberg School of Public Health, Johns Hopkins University, Baltimore, MD, USA. ${ }^{3}$ Save the Children, Bangladesh country office, Dhaka, Bangladesh. ${ }^{4}$ Department of Global Health, Save the Children-USA, Washington, DC, USA. International Centre for Diarrhoeal Disease Research, Dhaka, Bangladesh.

\section{Received: 18 September 2017 Accepted: 22 February 2018}

\section{Published online: 09 March 2018}

\section{References}

1. Liu L, Hill K, Oza S, Hogan D, Chu Y, Cousens S, Mathers C, Stanton C, Lawn J, Black RE. Levels and causes of mortality under age five years. In: Black RE, Laxminarayan R, Temmrman M, Walker N, editors. Reproductive, maternal, newborn, and child health. Volume 1. Third ed. Washington DC: World Bank Group; 2016. p. 74

2. Oestergaard MZ, Inoue M, Yoshida S, Mahanani WR, Gore FM, Cousens S, Lawn JE, Mathers CD, United Nations Inter-Agency Group for Child Mortality E, the Child Health Epidemiology Reference G. Neonatal mortality levels for 193 countries in 2009 with trends since 1990: a systematic analysis of progress, projections, and priorities. PLoS Med. 2011;8(8):e1001080.

3. Lawn JE, Kinney MV, Black RE, Pitt C, Cousens S, Kerber K, Corbett E, Moran AC, Morrissey CS, Oestergaard MZ. Newborn survival: a multi-country analysis of a decade of change. Health Policy Plan. 2012;27(Suppl 3):iii6-28.

4. Lawn JE, Blencowe H, Oza S, You D, Lee AC, Waiswa P, Lalli M, Bhutta Z, Barros AJ, Christian P, et al. Every newborn: progress, priorities, and potential beyond survival. Lancet. 2014;384(9938):189-205.

5. UNICEF. Levels and trends in child mortality: report 2014. Estimates developed by the UN Inter-agency Group for Child Morality Estimation. New York: UNICEF; 2014

6. Black RE, Cousens S, Johnson HL, Lawn JE, Rudan I, Bassani DG, Jha P Campbell H, Walker CF, Cibulskis R, et al. Global, regional, and national causes of child mortality in 2008: a systematic analysis. Lancet. 2010; 375(9730):1969-87.

7. Oza S, Lawn JE, Hogan DR, Mathers C, Cousens SN. Neonatal cause-ofdeath estimates for the early and late neonatal periods for 194 countries: 2000-2013. Bull World Health Organ. 2015;93(1):19-28.

8. Bang AT, Paul VK, Reddy HM, Baitule SB. Why do neonates die in rural Gadchiroli, India? (part I): primary causes of death assigned by neonatologist based on prospectively observed records. J Perinatol. 2005;25(Suppl 1):S29-34

9. Baqui AH, Darmstadt GL, Williams EK, Kumar V, Kiran TU, Panwar D, Srivastava VK, Ahuja R, Black RE, Santosham M. Rates, timing and causes of neonatal deaths in rural India: implications for neonatal health programmes. Bull World Health Organ. 2006;84(9):706-13.

10. Darmstadt GL, Walker N, Lawn JE, Bhutta ZA, Haws RA, Cousens S. Saving newborn lives in Asia and Africa: cost and impact of phased scale-up of interventions within the continuum of care. Health Policy Plan. 2008;23(2): 101-17.

11. Baqui AH, El-Arifeen S, Darmstadt GL, Ahmed S, Williams EK, Seraji HR, Mannan I, Rahman SM, Shah R, Saha SK, et al. Effect of community-based newborn-care intervention package implemented through two servicedelivery strategies in Sylhet district, Bangladesh: a cluster-randomised controlled trial. Lancet. 2008;371(9628):1936-44.

12. Darmstadt GL, Bhutta ZA, Cousens S, Adam T, Walker N, de Bernis L, Lancet Neonatal Survival Steering T. Evidence-based, cost-effective interventions: how many newborn babies can we save? Lancet. 2005;365(9463):977-88.

13. Baqui AH, Saha SK, Ahmed AS, Shahidullah M, Quasem I, Roth DE Samsuzzaman AK, Ahmed W, Tabib SM, Mitra DK, et al. Safety and efficacy of alternative antibiotic regimens compared with 7 day injectable procaine benzylpenicillin and gentamicin for outpatient treatment of neonates and young infants with clinical signs of severe infection when referral is not possible: a randomised, open-label, equivalence trial. Lancet Glob Health. 2015;3(5):e279-87.

14. African Neonatal Sepsis Trial g, Tshefu A, Lokangaka A, Ngaima S, Engmann C, Esamai F, Gisore P, Ayede Al, Falade AG, Adejuyigbe EA, et al. Simplified antibiotic regimens compared with injectable procaine benzylpenicillin plus gentamicin for treatment of neonates and young infants with clinical signs of possible serious bacterial infection when referral is not possible: a randomised, open-label, equivalence trial. Lancet. 2015;385(9979):1767-76.

15. Ganatra HA, Zaidi AK. Neonatal infections in the developing world. Semin Perinatol. 2010;34(6):416-25.

16. Mullany LC, El Arifeen S, Winch PJ, Shah R, Mannan I, Rahman SM, Rahman MR, Darmstadt GL, Ahmed S, Santosham M, et al. Impact of $4.0 \%$ chlorhexidine cleansing of the umbilical cord on mortality and omphalitis among newborns of Sylhet, Bangladesh: design of a community-based cluster randomized trial. BMC Pediatr. 2009;9:67.

17. Arifeen SE, Mullany LC, Shah R, Mannan I, Rahman SM, Talukder MR, Begum N, Al-Kabir A, Darmstadt GL, Santosham M, et al. The effect of cord cleansing with chlorhexidine on neonatal mortality in rural Bangladesh: a community-based, cluster-randomised trial. Lancet. 2012:379(9820):1022-8.

18. Young Infants Clinical Signs Study Group. Clinical signs that predict severe illness in children under age 2 months: a multicentre study. Lancet. 2008; 371:135-42.

19. Yan Y, Moore RD, Hoover DR. Competing risk adjustment reduces overestimation of opportunistic infection rates in AIDS. J Clin Epidemiol. 2000;53(8):817-22.

20. Coviello V, Boggess M. Cumulative incidence estimation in the presence of competing risks. Stata J. 2004:4:103-12.

21. Liang KY, Zeger SL. Longitudinal data analysis using generalized linear models. Biometrika. 1986;73(1):13-22.

22. Zeger SL, Liang KY. Longitudinal data analysis for discrete and continuous outcomes. Biometrics. 1986;42(1):121-30.

23. Yelland LN, Salter AB, Ryan P. Performance of the modified Poisson regression approach for estimating relative risks from clustered prospective data. Am J Epidemiol. 2011:174(8):984-92.

24. Levy PS. Missing Data Estimation,"Hot Deck" and "Cold Deck". In: Armitage P, Colton T, editors. Encyclopedia of Biostatistics. Second ed. Chichester: Wiley; 2005.

25. Vyas S, Kumaranayake L. Constructing socio-economic status indices: how to use principal components analysis. Health Policy Plan. 2006:21(6):459.

26. Vieira TO, Vieira GO, Giugliani ER, Mendes CM, Martins CC, Silva LR. Determinants of breastfeeding initiation within the first hour of life in a Brazilian population: cross-sectional study. BMC Public Health. 2010;10:760

27. StatCorp. Stata statistical software: release 12. College Station: Stata Corporation; 2011

28. Baqui AH, Arifeen SE, Williams EK, Ahmed S, Mannan I, Rahman SM, Begum N, Seraji HR, Winch PJ, Santosham M, et al. Effectiveness of home-based management of newborn infections by community health workers in rural Bangladesh. Pediatr Infect Dis J. 2009;28(4):304-10.

29. Seale AC, Blencowe H, Manu AA, Nair H, Bahl R, Qazi SA, Zaidi AK, Berkley JA, Cousens SN, Lawn JE, et al. Estimates of possible severe bacterial infection in neonates in sub-Saharan Africa, south Asia, and Latin America for 2012: a systematic review and meta-analysis. Lancet Infect Dis. 2014; 14(8):731-41.

30. Herbst A, Kallen K. Time between membrane rupture and delivery and septicemia in term neonates. Obstet Gynecol. 2007;110(3):612-8.

31. Shah GS, Budhathoki S, Das BK, Mandal RN. Risk factors in early neonatal sepsis. Kathmandu Univ Med J (KUMJ). 2006;4(2):187-91. 
32. Liben ML, Yesuf EM. Determinants of early initiation of breastfeeding in Amibara district, Northeastern Ethiopia: a community based cross-sectional study. International Breastfeeding Journal. 2016;11:7.

33. Alam N, David PH. Infant and child mortality in Bangladesh: age-specific effects of previous child's death. J Biosoc Sci. 1998;30(3):333-48.

34. Lee AC, Mullany LC, Tielsch JM, Katz J, Khatry SK, LeClerq SC, Adhikari RK, Shrestha SR, Darmstadt GL. Risk factors for neonatal mortality due to birth asphyxia in southern Nepal: a prospective, community-based cohort study. Pediatrics. 2008;121(5):e1381-90.

35. Kitsantas $P$. The impact of a previous child death on subsequent birth outcomes in a racially/ethnically diverse sample. Archives-The International Journal of Medicine. 2009;2(1):204-7.

36. Mavalankar DV, Gray RH, Trivedi CR, Parikh VC. Risk factors for small for gestational age births in Ahmedabad, India. J Trop Pediatr. 1994;40(5): 285-90.

37. Aaby P, Bukh J, Lisse IM, Seim E, de Silva MC. Increased perinatal mortality among children of mothers exposed to measles during pregnancy. Lancet. 1988;1(8584):516-9.

38. Jatrana S. Infant survival at" low cost": the effect of colostrum on infant mortality in rural North India. Genus. 2003;59:181-200.

39. Graham NM. The epidemiology of acute respiratory infections in children and adults: a global perspective. Epidemiol Rev. 1990;12:149-78.

40. Sikolia DN, Mwololo K, Cherop H, Hussein A, Juma M, Kurui J, Bwika A, Seki I, Osaki Y. The prevalence of acute respiratory infections and the associated risk factors: a study of children under five years of age in Kibera Lindi village, Nairobi, Kenya. J Natl Inst Public Health. 2002;51:1.

41. Thaver D, Zaidi A. Neonatal infections in south Aisa. In: Bhutta Z, editor. Perinatal and newborn care in South Asia: priorities for action. Oxford: Oxford Unversity Press; 2007.

42. Edmond K, Zaidi A. New approaches to preventing, diagnosing, and treating neonatal sepsis. PLoS Med. 2010;7(3):e1000213.

43. Bhutta ZA, Darmstadt GL, Hasan BS, Haws RA. Community-based interventions for improving perinatal and neonatal health outcomes in developing countries: a review of the evidence. Pediatrics. 2005;115(2 Suppl):519-617.

44. Bhakoo ON, Singh M. Perinatal risk factors in neonatal bacterial sepsis. Indian J Pediatr. 1988:55(6):941-6.

45. Salem SY, Sheiner E, Zmora E, Vardi H, Shoham-Vardi I, Mazor M. Risk factors for early neonatal sepsis. Arch Gynecol Obstet. 2006;274(4):198-202.

46. Blencowe H, Cousens S, Mullany LC, Lee AC, Kerber K, Wall S, Darmstadt GL, Lawn JE. Clean birth and postnatal care practices to reduce neonatal deaths from sepsis and tetanus: a systematic review and Delphi estimation of mortality effect. BMC Public Health. 2011;11(Suppl 3):S11.

47. Wong N, Hunt L, Marlow N. Risk factors for developing neonatal septicaemia at a Malaysian hospital. J Trop Pediatr. 1997;43(1):54-8.

48. Washburn TC, Medearis DN Jr, Childs B. Sex differences in susceptibility to infections. Pediatrics. 1965;35:57-64.

49. Leal YA, Alvarez-Nemegyei J, Velazquez JR, Rosado-Quiab U, DiegoRodriguez N, Paz-Baeza E, Davila-Velazquez J. Risk factors and prognosis for neonatal sepsis in southeastern Mexico: analysis of a four-year historic cohort follow-up. BMC Pregnancy Childbirth. 2012;12:48.

50. Ojukwu JU, Abonyi LE, Ugwu J, Orji IK. Neonatal septicemia in high risk babies in south-eastern Nigeria. J Perinat Med. 2006;34(2):166-72.

51. Kamath-Rayne BD, Macguire ER, McClure EM, Goldenberg RL, Jobe AH. Clinical algorithms for the identification of sick newborns in communitybased settings. Acta Paediatr. 2012;101(4):344-51.

52. Lawn JE, Cousens S, Zupan J. Lancet neonatal survival steering T: 4 million neonatal deaths: when? where? why? Lancet. 2005;365(9462):891-900.

53. National Institute of Population Research and Training. Bangladesh Demographic and Health Survey 2014. Dhaka, Rockvile: NIPORT, Mitra and Associates, and ICF International; 2016.

54. Government of Bangladesh (GOB). Bangladesh Every Newborn Action Plan (BENAP). Dhaka: Ministry of Health and Family Welfare (MOHFW); 2015.

55. Government of Bangladesh (GOB). Operational plan of the 4th Health, Nutrition and Population Sector Program (2017-2022). Dhaka: Ministry of Health and Family Welfare (MOHFW); 2017.

\section{Submit your next manuscript to BioMed Central and we will help you at every step:}

- We accept pre-submission inquiries

- Our selector tool helps you to find the most relevant journal

- We provide round the clock customer support

- Convenient online submission

- Thorough peer review

- Inclusion in PubMed and all major indexing services

- Maximum visibility for your research

Submit your manuscript at www.biomedcentral.com/submit
) Biomed Central 